\title{
PREVALENCE AND IMPACT OF PAINFUL DIABETIC PERIPHERAL NEUROPATHY IN PATIENTS WITH TYPE-2 DIABETES MELLITUS WITH LOW ECONOMIC STATUS
}

\author{
NISHITHA CHOWDARY DL ${ }^{1}$, SOMASUNDARAM I ${ }^{2 *}$ \\ ${ }^{1}$ Department of Pharmacy Practice, School of Pharmaceutical Sciences, Vels Institute of Science, Technology and Advanced Studies, \\ Vels University, Chennai, Tamil Nadu, India. ${ }^{2}$ Department of Parmacetics, School of Pharmaceutical Sciences, Vels Institute of Science, \\ Technology and Advanced Studies, Vels University, Chennai, Tamil Nadu, India. Email: somous0926@gmail.com
}

Received: 01 August 2017, Revised and Accepted: 21 March 2018

ABSTRACT

Objectives: The objectives of the study were to study the prevalence of painful diabetic peripheral neuropathy (PDPN) in patients with type-2 diabetes and to access the health-related quality of life of patient by collecting and documenting the information of patient using sf-15 questionnaire.

Methods: The present study involves prospective analysis of quality of life in both men and women with PDPN with type-2 diabetes. The methodology involves collection and documentation of patients medical and medication history, blood glucose levels, and duration of diabetes. Further, the quality of life of patient is documented using Michigan neuropathic scaling instrument (sf-15 questionnaire) through which we can assess the impact of PDPN.

Results: It can be seen that there are no significant changes in the prevalence of PDPN when compared gender wise and based on age, but there are an extremely statistically significant $\left({ }^{*} \mathrm{p}<0.05\right)$ values obtained when the presence of PDPN is compared between duration of diabetes.

Conclusion: Patients with duration of diabetes type-2 between 5 and 10 years are mostly presented with PDPN. Early detection, nutritious diet, and patient counseling help in management of PDPN.

Keywords: Painful diabetic peripheral neuropathy, Type-2 diabetes, Questionnaire, Quality of life, Patient counseling.

(C) 2018 The Authors. Published by Innovare Academic Sciences Pvt Ltd. This is an open access article under the CC BY license (http://creativecommons. org/licenses/by/4. 0/) DOI: http://dx.doi.org/10.22159/ajpcr.2018.v11i6.21752

\section{INTRODUCTION}

Peripheral neuropathy is the most common complication of type-2 diabetes [1]. Peripheral neuropathy can present as loss of sensation which may cause foot ulcers, which is the leading cause of amputations [2]. Peripheral neuropathy may be asymptomatic. It may have both negative and positive symptoms; negative symptoms include loss of sensation and loss of strength and positive symptoms include pain, which is then termed as painful diabetic peripheral neuropathy (PDPN) [3]. PDPN can last for years and severely impair quality of life of patients when left untreated [4]. Longterm use of metformin may cause nerve damage which leads to neuropathy with both positive and negative symptoms [5]. Vitamin B12 supplementation may help in restoring nerve function and also reduction of neuropathic pain [6].

Mark Davies have conducted a cross-sectional descriptive study "the prevalence, severity, and impact of PDPN in type-2 diabetes" containing two phases, and concluded that the study showed a prevalence of PDPN of $26.4 \%$. Having PDPN has a significant negative effect on quality of life, and increasing neuropathy is associated with an increasing risk of developing PDPN [7]. Deepika Bansal conducted a prospective study called "prevalence and risk factors of the development of peripheral neuropathy in type- 2 diabetes mellitus in tertiary care unit" and concluded the study showed a high prevalence (29.2\%) of DPN among north Indian type 2 diabetes mellitus patients. Thus, timely screening with earlier detection and intervention would be useful in preventing the progression of neuropathy [8].

The main aim of this study is to assess the quality of life of patients with PDPN and its impact on their daily life and determine the prevalence of PDPN in patients with type-2 diabetes. The impact of PDPN can be determined using score obtained by Michigan neuropathic scale (mnsi sf-15 questionnaire).

\section{MATERIALS AND METHODS}

The study is carried out in a tertiary care hospital.

Study period

The study of period was 6 months.

Study instrument

Case report form, MNSI (sf-15 questionnaire).

\section{Inclusion criteria}

All male and female patients aged above 30 years with type- 2 diabetes were included in this study.

\section{Exclusion criteria}

Type 1 diabetes mellitus, gestational diabetes patients, lactating mother, and chronically ill patients were excluded from the study.

\section{Methods}

Study design

This method involves prospective analysis of quality of life of both male and female patients with PDPN with type- 2 diabetes. The study is carried out by collection and documentation of general information of patient including personal history, medical and medication history, duration of diabetes, and blood glucose levels. The quality of life of patient and impact of pain is documented using MNSI questionnaire.

\section{Study instrument}

MNSI questionnaire (part-1) include consists of 15 "yes or no" questions on foot sensation including pain, numbness, and temperature sensitivity. The information is collected from each and every patient. Finally, the documented questionnaire is documented and evaluated for the presence or absence of PDPN. The study was conducted after 
obtaining informed consent form from the patient. This study was approved by the institutional ethics committee IEC/DOPV/2016/14

\section{RESULTS}

The following results were obtained when the data were collected from the patient.

Of 100 type- 2 diabetic patients involved in the study, 57 patients have PDPN (male - 26, female - 31) and 43 patients do not have PDPN (male - 17, female - 26) (Table 1 and Fig. 1).

Of 100 patients, 57 patients are reported with PDPN where 16 patients (28\%) were in age group of 35-45 years, 20 patients (35\%) were in age group of 46-55 years, and 21 patients (36\%) were in age group of 56-65 years (Table 2 and Fig. 2).

Of 100 diabetic patients, patients who are having diabetes from up to 10 years, 30 members have presented with PDPN and 34 patients do not have PDPN. Patients who are having diabetes from more than 10 years, 27 have presented with PDPN and 9 patients do not have PDPN (Table 3 and Fig. 3).

Table 4 and Fig. 4 summarizes there is no significance of the prevalence of PDPN when related to gender, in the given population. With 95\% confidence interval $(\mathrm{CI}){ }^{*} \mathrm{p}=0.5432$ [NS], two-sided study using Chisquare, statistically not significant $(\alpha<0.05)$.

Table 5 and Fig. 5 summarizes there is no significance of the prevalence of PDPN when related to age group in given population. With $95 \% \mathrm{CI}$ ${ }^{*} \mathrm{p}=0.2665$ [NS], two-sided study using Chi-square, statistically not significant $(\alpha<0.05)$

Table 6 and Fig. 6 summarizes there is high significance of the presence of PDPN in the given population, as most of the patients participated

Table 1: Presence and absence of PDPN in patients with type-2 diabetes

\begin{tabular}{lll}
\hline Gender & Patients with PDPN & Patients without PDPN \\
\hline Male & 26 & 17 \\
Female & 31 & 26 \\
\hline PDPN: Painful diabetic peripheral neuropathy &
\end{tabular}

PDPN: Painful diabetic peripheral neuropathy

Table 2: Age-based population distribution in patients with PDPN

\begin{tabular}{ll}
\hline Age in years & Population (\%) \\
\hline $35-45$ & $16(28)$ \\
$46-55$ & $20(35)$ \\
$56-65$ & $21(36)$ \\
\hline
\end{tabular}

PDPN: Painful diabetic peripheral neuropathy

Table 3: Comparison of duration of diabetes and presence of PDPN

\begin{tabular}{lll}
\hline Duration (years) & Presence of PDPN & Absence of PDPN \\
\hline$<10$ & 30 & 34 \\
$>10$ & 27 & 9 \\
\hline
\end{tabular}

PDPN: Painful diabetic peripheral neuropathy

Table 4: Prevalence of PDPN in relation to gender in population

\begin{tabular}{llll}
\hline Gender & Patients with PDPN & Patients without PDPN & Total \\
\hline Male & 26 & 17 & 43 \\
female & 31 & 26 & 57 \\
\hline
\end{tabular}

PDPN: Painful diabetic peripheral neuropathy in study belonged to group having diabetes for $<10$ years. With $95 \%$ $\mathrm{CI}{ }^{*} \mathrm{p}=0.0064$, two-sided study using Chi-square, statistically significant $(\alpha<0.05, p=0.0064)$.

\section{DISCUSSION}

PDPN is caused due to nerve damage [9]. As patients with type-2 diabetes are mostly prescribed with metformin for regulating the sugar levels, long-standing use of metformin is also one of the root causes of loss of nerve function which causes malabsorption of Vitamin B12 [10]. Low serum levels of Vitamin B12 are observed in patients who take $2 \mathrm{~g}$ of metformin per day for at least 2 years [11]. Uncontrolled sugar levels in blood also causes nerve damage leading to neuropathy, but sugar levels can be controlled using hypoglycemic agents on time and maintaining healthy food habits and regular exercise [12] Although the patients with poor economic status are given with free treatment and vitamin supplements, lack of knowledge regarding the use of the drug, and less patient education, many patients with type-2 diabetes fail to take nutritious food and vitamin supplementations, especially B12 [13]. Results of the project show that a total of 100 diabetic patients 57 are diagnosed to have PDPN presenting a prevalence of $57 \%, 95 \% \mathrm{CI}$ of studied sample, these results were similar with the results reported by dr. farooq ahmed (vol. 88 no. 16 Supplement P4.050) [14]. The mean age for the presence of PDPN in type-2 diabetic patients is 51.3 years. Female patients are reported relatively high than male patients. Most of the patients with PDPN are in age group of 51-65 years [15]. Patients who are having diabetes for more than 10 years are presented with less symptoms of PDPN and most of the patients with PDPN have diabetes for $<10$ years [16]. This is due to improper intake of medication, lack of nutritional intake, lack of B12 supplementation, and many such factors [17]. Patients with diabetes for more than 10 years have been taking proper B12 supplementation and limited amount of food which made them lead a healthy lifestyle. We can reduce the prevalence of PDPN by educating the patients regarding regular medication intake,

\section{Table 5: Prevalence of PDPN in relation with age group}

\begin{tabular}{llll}
\hline Age group & $\begin{array}{l}\text { Patients with } \\
\text { PDPN }\end{array}$ & $\begin{array}{l}\text { Patients without } \\
\text { PDPN }\end{array}$ & Total \\
\hline $35-50$ & 23 & 22 & 45 \\
$51-65$ & 34 & 21 & 55 \\
\hline PDPN: Painful diabetic perpheral
\end{tabular}

Table 6: Prevalence of PDPN in relation with duration of type-2 diabetes

\begin{tabular}{llll}
\hline Duration (years) & $\begin{array}{l}\text { Presence of } \\
\text { PDPN }\end{array}$ & $\begin{array}{l}\text { Absence of } \\
\text { PDPN }\end{array}$ & Total \\
\hline$<10$ & 30 & 34 & 64 \\
$>10$ & 27 & 9 & 36 \\
\hline
\end{tabular}

PDPN: Painful diabetic peripheral neuropathy

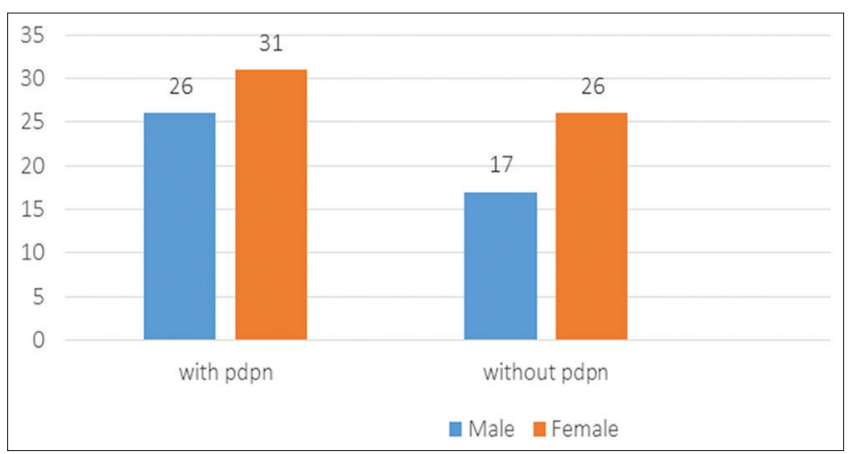

Fig. 1: Presence and absence of painful diabetic peripheral neuropathy in patients with type- 2 diabetes 


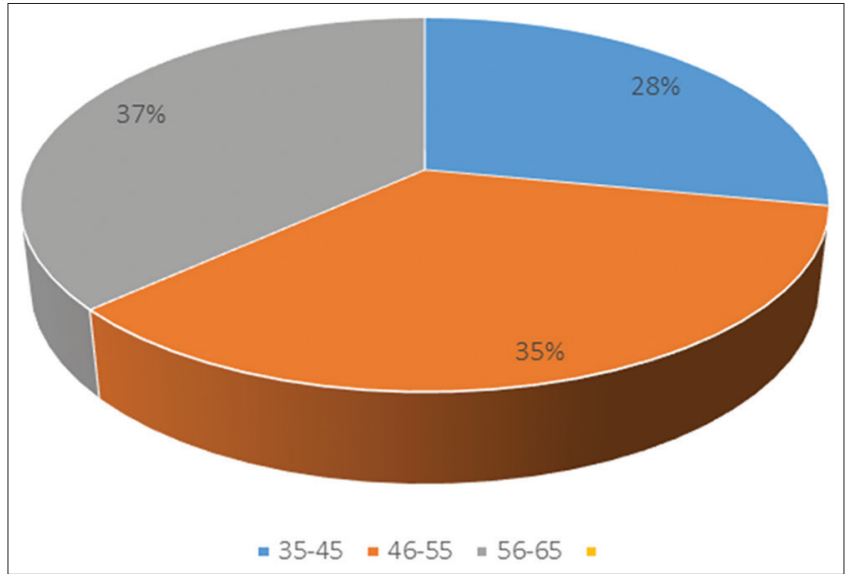

Fig. 2: Age-based population distribution in patients with painful diabetic peripheral neuropathy

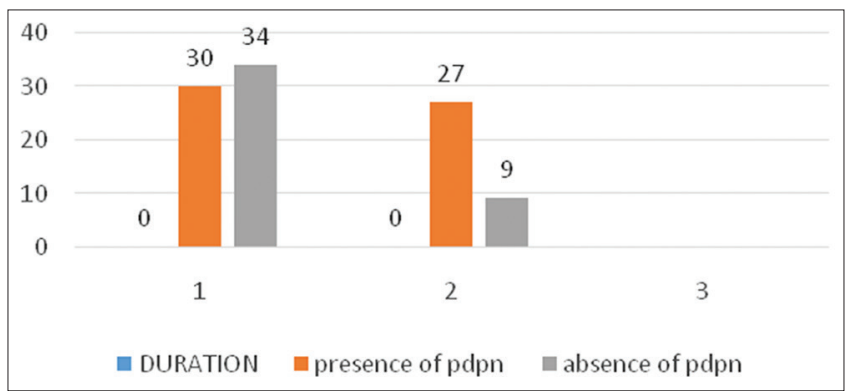

Fig. 3: Comparison of duration of diabetes and presence of painful diabetic peripheral neuropathy

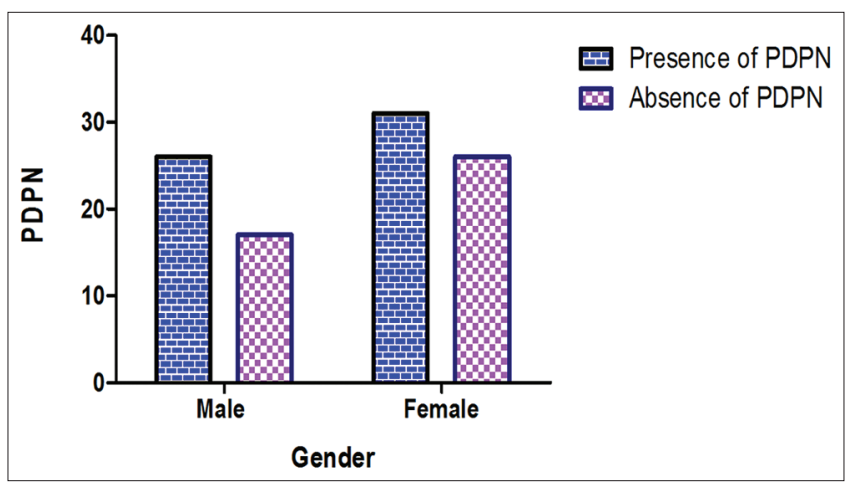

Fig. 4: Prevalence of painful diabetic peripheral neuropathy in relation to gender in population

nutritional intake to be taken, maintaining glucose levels in the body, and modifications regarding lifestyle.

\section{CONCLUSION}

Patients with type-2 diabetes for more than 2 years with poor economic status lacked proper nutritional supplementation, especially Vitamin B12, which is leading cause of neuropathy. PDPN showed a negative impact on patients' quality of life and effected the basic regular activities performed by the patient.

\section{ACKNOWLEDGMENT}

We are indebted to Vels Institute of Science, Technology, and Advanced Studies, Chennai, for giving us permission and encouragement for doing the work. We are also grateful for providing all the facilities and support during the period of our study.

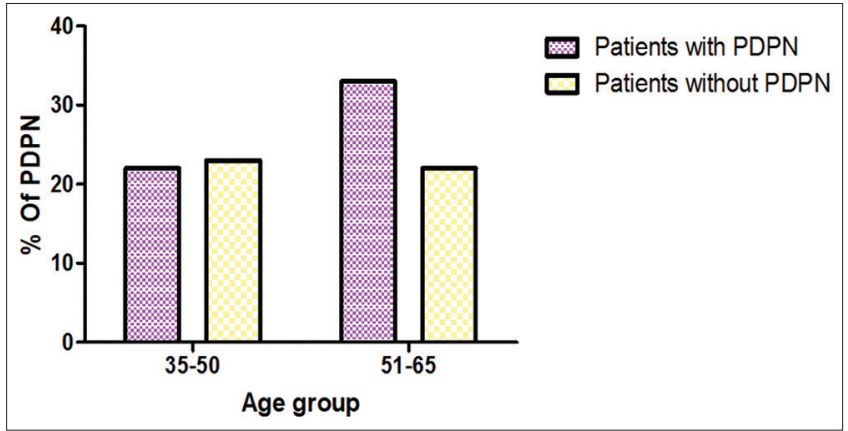

Fig. 5: Prevalence of painful diabetic peripheral neuropathy in relation with age group

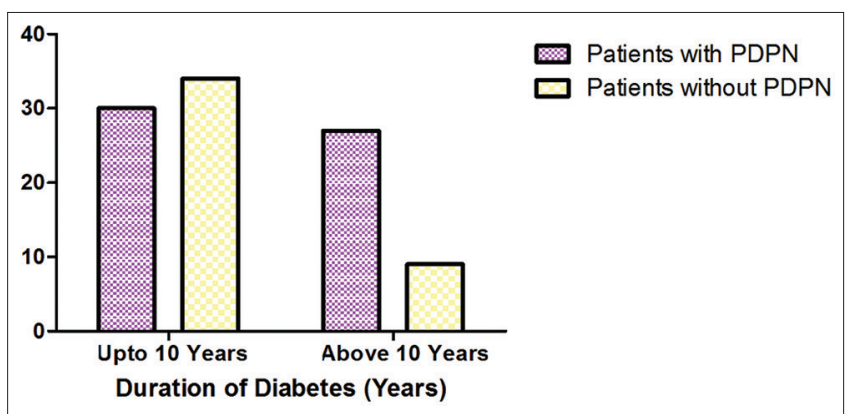

Fig. 6: Prevalence of painful diabetic peripheral neuropathy in relation with duration of type- 2 diabetes

\section{REFERENCES}

1. Seema T, Neha S. Update on neuropathic pain models. Int J Pharm Pharm Sci 2016;8:11-6.

2. Senthilkumar, Anandhasayanam A, Safil KM, Shemimol S. Comparative study on the effectiveness of angiotensin converting enzyme inhibitors (aceis) and angiotensin receptor blockers (arbs) in diabetic nephropathy in Type 2 diabetes mellitus patients. Int J Pharm Pharm Sci 2016;8:289-92.

3. Cramer JA, Benedict A, Muszbek N, Keskinaslan A, Khan ZM. The significance of compliance and persistence in the treatment of diabetes, hypertension and dyslipidaemia: A review. Int J Clin Pract 2007;62:76-87.

4. Thomas PK. Classification, differential diagnosis, and staging of diabetic peripheral neuropathy. A review article based on peripheral neuropathy. Diabetes 1997:46 Suppl 2:54S-7.

5. Greenbaum D. Observations on the homogeneous nature and pathogenesis of diabetic neuropathy. Brain 1964;87:215-32.

6. Thomas PK, Griffin JW. Neuropathies predominantly affecting sensory or motor function. In: Peripheral Nerve Disorders. Oxford: Butterworths; 1995. p. 59-94.

7. Mahajan R, Gupta K. Revisiting metformin: Annual vitamin B12 supplementation may become mandatory with long-term metformin use. J Young Pharm 2010;2:428-9.

8. Farouk AS, Alkandri ME, Al-Hashel JM, Alhajerie D, Alroughani R. Prevalence and treatment options for diabetic neuropathic pain in Kuwait. Neurology 2017;88:16.

9. Bansal D, Gudala K, Muthyala H, Esam HP, Nayakallu R, Bhansali A, et al. Prevalence and risk factors of development of peripheral diabetic neuropathy in Type 2 diabetes mellitus in a tertiary care setting. J Diabetes Investig 2014;5:714-21.

10. Jayaprakash P, Bhansali A, Bhansali A, Dutta P, Anantharaman R, Shanmugasundar G, et al. Validation of bedside methods in evaluation of diabetic peripheral neuropathy. Indian J Med Res 2011;133:645-9.

11. Benbow SJ, Wallymahmed ME, MacFarlane IA. Diabetic peripheral neuropathy and quality of life. QJM 1998;91:733-7.

12. Tesfaye S, Selvarajah D. Advances in the epidemiology, pathogenesis and management of diabetic peripheral neuropathy. Diabetes Metab Res Rev 2012;28 Suppl 1:8-14.

13. Al-Geffari M. Comparison of different screening tests for diagnosis of diabetic peripheral neuropathy in primary health care setting. Int J Health Sci (Qassim) 2012;6:127-34. 
14. Swislocki A, Orth M, Bales M, Weisshaupt J, West C, Edrington J, et al. A randomized clinical trial of the effectiveness of photon stimulation on pain, sensation, and quality of life in patients with diabetic peripheral neuropathy. J Pain Symptom Manage 2010;39:88-99.

15. Partanen J, Niskanen L, Lehtinen J, Mervaala E, Siitonen O, Uusitupa $\mathrm{M}$, et al. Natural history of peripheral neuropathy in patients with non-insulin-dependent diabetes mellitus. N Engl J Med
1995;333:89-94

16. Schmader KE. Epidemiology and impact on quality of life of post herpetic neuralgia and painful diabetic neuropathy. Clin J Pain 2002;18:350-4.

17. Galer BS, Gianas A, Jensen MP. Painful diabetic polyneuropathy: Epidemiology, pain description, and quality of life. Diabetes Res Clin Pract 2000;47:123-8. 